\title{
7 Hospital Evaluations by Social Media: A Comparative Analysis of Facebook Ratings among Performance Outliers
}

\author{
McKinley Glover, MD MHS ${ }^{7}$, Omid Khalilzadeh, MD MPH', Garry Choy, MD MBA', \\ Anand M. Prabhakar, MD' ${ }^{2}$, Pari V. Pandharipande, MD MPH ${ }^{1,3}$, \\ and G. Scott Gazelle, MD MPH PhD ${ }^{1,3}$
}

\begin{abstract}
'Department of Radiology, Massachusetts General Hospital, Harvard Medical School, Boston, MA, USA; ${ }^{2}$ Division of Cardiovascular Imaging, Massachusetts General Hospital, Harvard Medical School, Boston, MA, USA; ${ }^{3}$ Institute for Technology Assessment, Massachusetts General Hospital, Harvard Medical School, Boston, MA, USA.
\end{abstract}

BACKGROUND: An increasing number of hospitals and health systems utilize social media to allow users to provide feedback and ratings. The correlation between ratings on social media and more conventional hospital quality metrics remains largely unclear, raising concern that healthcare consumers may make decisions on inaccurate or inappropriate information regarding quality.

OBJECTIVES: The purpose of this study was to examine the extent to which hospitals utilize social media and whether user-generated metrics on Facebook ${ }^{\circledR}$ correlate with a Hospital Compare ${ }^{\circledR}$ metric, specifically 30-day all cause unplanned hospital readmission rates.

DESIGN AND PARTICIPANTS: This was a retrospective cross-sectional study conducted among all U.S. hospitals performing outside the confidence interval for the national average on 30-day hospital readmission rates as reported on Hospital Compare. Participants were 315 hospitals performing better than U.S. national rate on 30-day readmissions and 364 hospitals performing worse than the U.S. national rate.

MAIN MEASURES: The study analyzed ratings of hospitals on Facebook's five-star rating scale, 30-day readmission rates, and hospital characteristics including beds, teaching status, urban vs. rural location, and ownership type.

KEY RESULTS: Hospitals performing better than the national average on 30-day readmissions were more likely to use Facebook than lower-performing hospitals (93.3 \% vs. $83.5 \% ; \mathrm{p}<0.01)$. The average rating for hospitals with low readmission rates $(4.15 \pm 0.31)$ was higher than that for hospitals with higher readmission rates $(4.05 \pm 0.41, \mathrm{p}<$ 0.01). Major teaching hospitals were 14.3 times more likely to be in the high readmission rate group. A onestar increase in Facebook rating was associated with increased odds of the hospital belonging to the low readmission rate group by a factor of 5.0 (CI: 2.6-10.3, p < 0.01), when controlling for hospital characteristics and Facebook-related variables.

CONCLUSIONS: Hospitals with lower rates of 30-day hospital-wide unplanned readmissions have higher ratings on Facebook than hospitals with higher readmission rates. These findings add strength to the concept that

Received November 18, 2014

Revised January 12, 2015

Accepted February 2, 2015

Published online March 7, 2015 aggregate measures of patient satisfaction on social media correlate with more traditionally accepted measures of hospital quality.

KEY WORDS: Performance measurement; Patient satisfaction; Consumer health informatics.

J Gen Intern Med 30(10): 1440-6

DOI: $10.1007 / \mathrm{s} 11606-015-3236-3$

(C) Society of General Internal Medicine 2015

\section{INTRODUCTION}

Social media continues to transform the way that organizations and consumers interact. Facebook ${ }^{\mathbb{B}}$, the world's largest social networking site, has 1.2 billion monthly users, indicating that the scope of social media extends beyond traditional marketing platforms. ${ }^{1}$ Healthcare lags behind other industries in the use of social media, which is partly attributable to unique ethical and legal issues, including controlling the flow of information, patient privacy, and protection of the patientprovider relationship. ${ }^{2-7}$ Nevertheless, healthcare social media has evolved from simple information-sharing functions to addressing complex public health problems such as healthcare quality and safety, disaster preparedness, and pandemic surveillance. $^{8-12}$

The Office of Health Information Technology within the U.S. Department of Health and Human Services acknowledges the importance of tracking and responding to social media's growing role in healthcare. ${ }^{13}$ Shared experiences about satisfaction and quality of healthcare organizations and providers posted online may influence consumers' healthcare decision-making in the coming years. The simplicity of social media as a healthcare information resource - in comparison to more challenging and conflicting modes of public reporting of healthcare quality data - may add value for consumers seeking to make sense of complex information. ${ }^{14,15}$ In fact, public reporting of healthcare outcomes is largely ignored by consumers, at least in part due to accessibility and comprehensibility issues. ${ }^{16,17}$ In 2008 , less than $10 \%$ of Americans used information comparing the quality of health insurance plans (9\%), hospitals (7\%), or doctors (6\%) to make healthcarerelated decisions, and only $6 \%$ were aware of Hospital 
Compare. ${ }^{18}$ Therefore, ensuring the accuracy of quality metrics of healthcare organizations and providers on social media sites is important to all stakeholders. ${ }^{15}$

In November 2013, technology Web sites began reporting that Facebook was providing organizations the option of allowing users to post ratings (1-5 stars) on their Facebook pages. ${ }^{19}$ The extent to which these ratings are related to hospital quality or patient satisfaction is unknown. Additionally, the potential impact of user-generated metrics on healthcare consumer decision-making and market share is unclear. However, a study from Harvard Business School demonstrated that among Seattle area restaurants, a one-star increase in Yelp ${ }^{\circledR}$ ratings was associated with a 5-9\% increase in revenue. ${ }^{20}$ Average star ratings may serve as a simplifying heuristic to help consumers learn about quality in the face of complex information. ${ }^{20}$

To date, the majority of literature related to social media in healthcare has been qualitative, primarily focused on implications and applications. ${ }^{2}$ Few studies have provided quantitative analysis of social media utilization by healthcare organizations or the relationship between end-user metrics and hospital quality and/or outcomes. ${ }^{11,21,22}$ However, emerging studies suggest that feedback and ratings on social media and other online rating tools may be correlated with patient satisfaction and objective measures of hospital quality and safety ${ }^{23}$.

Our study investigates the use of Facebook among hospitals performing above or below the confidence interval of the national average for 30-day readmissions as reported on Hospital Compare. Endorsed by the National Quality Forum, 30-day readmissions are also the focus of healthcare cost and quality initiatives, including the Hospital Readmissions Reduction program. ${ }^{24-26}$ The purpose of this study was to determine whether hospitals with lower readmission rates were more likely to have higher ratings on Facebook than hospitals with high readmission rates.

\section{METHODS}

Publicly available cross-sectional data from Hospital Compare were accessed to identify performance measurements for all Medicare-certified hospitals on 30-day hospital-wide all-cause unplanned readmission rates $(\mathrm{HWR})^{25}$. Data collection for readmission rates encompassed the period from July 2011 through June 2012, the most recently available data at the time of study initiation. ${ }^{27}$ Only hospitals reported as performing "outside the expected national average" on 30-day HWR were included in order to evaluate for potential maximum differences between groups and to reduce administrative burden and time-associated bias related to collection of Facebook ratings, which can change rapidly. The statistical model used to calculate HWR and $95 \%$ confidence interval estimates is reviewed elsewhere. $^{28}$

Each hospital name, as listed in Hospital Compare, was entered into an Internet search tool $\left(\right.$ Google $\left.{ }^{\circledR}\right)$ to locate its
Web page, which was then searched for a hyperlink to Facebook. If the link was present, it was followed to the Facebook page and data were collected. Only Facebook Pages, which are designed to "enable public figures, businesses, organizations and other entities to create an authentic and public presence on Facebook" were included. ${ }^{29}$ Additional options for Facebook presence, including groups, check-in pages, community pages, and personal profiles, were excluded.

If there was no visible link to Facebook on the hospital Web page, additional methods were utilized, as follows: 1) HTML code search of the Web page for the terms "Facebook," "connect," "follow," or "social"; 2) entering "Facebook" in the hospital Web page native search tool; 3) Internet search of the hospital name followed by "Facebook"; and 4) entering the hospital name within Facebook's native search tool. If a dedicated Facebook page was not found through these methods, the hospital was considered as not having a Facebook page. Given duplication of certain hospital names, Facebook pages were confirmed by address. Facebook data were obtained from January 26, 2014 through February 2, 2014.

Data from hospital/health system Facebook pages included 1) presence, number, and average of ratings (1-5), if available; 2) number of likes; 3 ) availability and number of check-ins ("were here" in which a user indicates having been physically present at that location); 4) date the hospital joined Facebook, as listed under the timeline data. If one or more hospital within a health system had the same Facebook page, all hospitals were deemed to utilize Facebook, but only one occurrence of the page was included in the Facebook data analyses to prevent double-counting.

Data on hospital size (beds), teaching status (major, minor, non-teaching), location (urban/rural), and total expenditures were collected from publicly available data (American Hospital Association DataViewer $)^{30}$ from February 20, 2014, through March 6, 2014.

Statistical analyses were performed using SPSS software (SPSS for Windows, Version 16.0; SPSS Inc., Chicago, IL, USA). Continuous variables are expressed as mean \pm standard deviation or median [interquartile range], as appropriate. Normality testing was performed using the KolmogorovSmirnov test. Between-group comparisons were performed with the independent-samples t-test, Mann-Whitney $U$ test, or Chi-square test, as appropriate. Multiple logistic regression analysis was used to assess the association between Facebook ratings and HWR performance when controlling for key variables. A p value $<0.05$ was considered statistically significant.

\section{RESULTS}

Characteristics of hospitals included in the study are presented in Table 1. Among all hospitals in the Hospital Compare 30day HWR dataset $(n=4805), 79 \%$ (3813) were reported 
Table 1 Characteristics of the Studied Hospitals

\begin{tabular}{|c|c|c|c|}
\hline & High-HWR Hospitals $(n=364)$ & Low-HWR Hospitals $(n=315)$ & $P$ value \\
\hline HWR & $18.05 \pm 0.82$ & $14.28 \pm 0.54$ & $<0.01$ \\
\hline Total number of hospital beds & $288[162-497]$ & $277[178-413]$ & NS \\
\hline Number of admissions & $14,441[7,576-23,977]$ & $13,806[7,790-20,978]$ & NS \\
\hline Number of outpatient visits & $180,583[82,722-396,970]$ & $192,983[124,616-351,404]$ & NS \\
\hline Number of personnel & $1,513[745-3,245]$ & $1,657[986-2,582]$ & NS \\
\hline Total expenses (million\$) & $238.5[110.4-519.6]$ & $289.5[155.7-428.7]$ & NS \\
\hline Teaching affiliation & & & $<0.01$ \\
\hline Major & $91(25.0 \%)$ & $25(7.9 \%)$ & \\
\hline Minor & $99(27.2 \%)$ & $133(42.2 \%)$ & \\
\hline Non-Teaching & $170(46.7 \%)$ & $155(49.2 \%)$ & \\
\hline Data not available & $4(1.1 \%)$ & $2(0.6 \%)$ & \\
\hline Location & & & $\mathrm{NS}$ \\
\hline Urban & $295(81.0 \%)$ & $264(83.8 \%)$ & \\
\hline Rural & $65(17.9 \%)$ & $49(15.6)$ & \\
\hline Data not available & $4(1.1 \%)$ & $2(0.6 \%)$ & \\
\hline Hospital Type & & & 0.04 \\
\hline Acute care hospitals & $356(97.8 \%)$ & $314(99.7 \%)$ & \\
\hline Critical access hospitals & $8(2.2 \%)$ & $1(0.3 \%)$ & \\
\hline Hospital ownership & & & $\mathrm{NS}$ \\
\hline Government - Federal & $3(0.8 \%)$ & $3(1.0 \%)$ & \\
\hline Government - Hospital District or Authority & $16(4.4 \%)$ & $21(6.7 \%)$ & \\
\hline Government - Local & $12(3.3 \%)$ & $12(3.8 \%)$ & \\
\hline Government - State & $19(5.2 \%)$ & $1(0.3 \%)$ & \\
\hline Physician & $0(0.0 \%)$ & $2(0.6 \%)$ & \\
\hline Proprietary & $71(19.5 \%)$ & $42(13.3 \%)$ & \\
\hline Voluntary non-profit - Church & $40(11.0 \%)$ & $52(16.5 \%)$ & \\
\hline Voluntary non-profit - Other & $37(10.2 \%)$ & $45(14.3 \%)$ & \\
\hline Voluntary non-profit Private & $166(45.6 \%)$ & $137(43.5 \%)$ & \\
\hline
\end{tabular}

Variables are presented as mean \pm standard deviation (SD), number (\%) or median [interquartile range]

NS nonsignificant

HWR hospital-wide unplanned readmission rate

having a readmission rate that was "no different than the U.S. national rate" $(15.4 \geq \mathrm{HWR} \geq 16.9), 315$ hospitals $(6.6 \%)$ were performing better than the national average on HWR (HWR $<15.4$, low-HWR group) and 364 (7.6 \%) were performing worse than the national rate (HWR $>16.9$, highHWR group). Data on HWR was "not available" for 196 hospitals (4.1\%); the number of patients/cases was too few for evaluation for 117 hospitals $(2.4 \%){ }^{31}$

No significant difference was found between the highand low-HWR hospitals with respect to the number of beds, admissions, outpatient visits, personnel, total expenses, or ownership status. Major teaching hospitals were more likely to be in the high-HWR hospital group $(p<0.001)$
Table 2 presents data on Facebook use and related variables by group. Among the low-HWR hospitals, $93.3 \%$ had a Facebook page (either a unique page or shared page with a larger healthcare organization), as compared to $82.4 \%$ of high-HWR hospitals $(p<0.001)$. Among the unique Facebook pages, the prevalence of allowing users to provide ratings on the five-star system was $81 \%$ in the high-HWR group and $82 \%$ in the low-HWR group. Figure 1 presents an example of a hospital Facebook page that utilized the five-star rating system. The number of ratings for low-HWR hospitals (349 [159-569]) was significantly $(p=0.01)$ higher than that for the high-HWR hospitals (248 [116-532]).

Among hospital Facebook pages utilizing the five-star rating system, the average Facebook rating for low-HWR

Table 2 Facebook Characteristics of the Studied Hospitals

\begin{tabular}{|c|c|c|c|}
\hline & High-HWR hospitals $(n=364)$ & Low-HWR hospitals $(n=315)$ & $P$ value \\
\hline \multicolumn{4}{|l|}{ Available on Facebook } \\
\hline Yes (unique) & $251(69.0 \%)$ & $254(80.6 \%)$ & $<0.01$ \\
\hline Yes (duplicates ${ }^{1}$ ) & $49(13.5 \%)$ & $40(12.7 \%)$ & \\
\hline No & $64(17.6 \%)$ & $21(6.7 \%)$ & \\
\hline Rating available on Facebook ${ }^{2}$ & $203(80.8 \%)$ & $207(81.5 \%)$ & NS \\
\hline Number of ratings & $248[116-532]$ & 349 [159-569] & 0.01 \\
\hline Rating out of five & $4.05 \pm 0.41$ & $4.15 \pm 0.31$ & $<0.01$ \\
\hline Number of likes & $1,695[701-3,827]$ & $2,017[969-4,238]$ & NS \\
\hline Number of check-ins & $5,493[1,084-17,725]$ & $6,748[1,695-15,367]$ & NS \\
\hline Months on Facebook & $43.53 \pm 15.30$ & $44.69 \pm 14.52$ & NS \\
\hline
\end{tabular}

Variables are presented as mean \pm standard deviation (SD), number (\%) or median [interquartile range]

NS nonsignificant

${ }^{1}$ Duplicates denote instances where a unique Facebook page was utilized by more than one hospital, typically hospitals within the same healthcare system.

${ }^{2}$ The percentage is calculated based the number of unique Facebook pages within each group. 


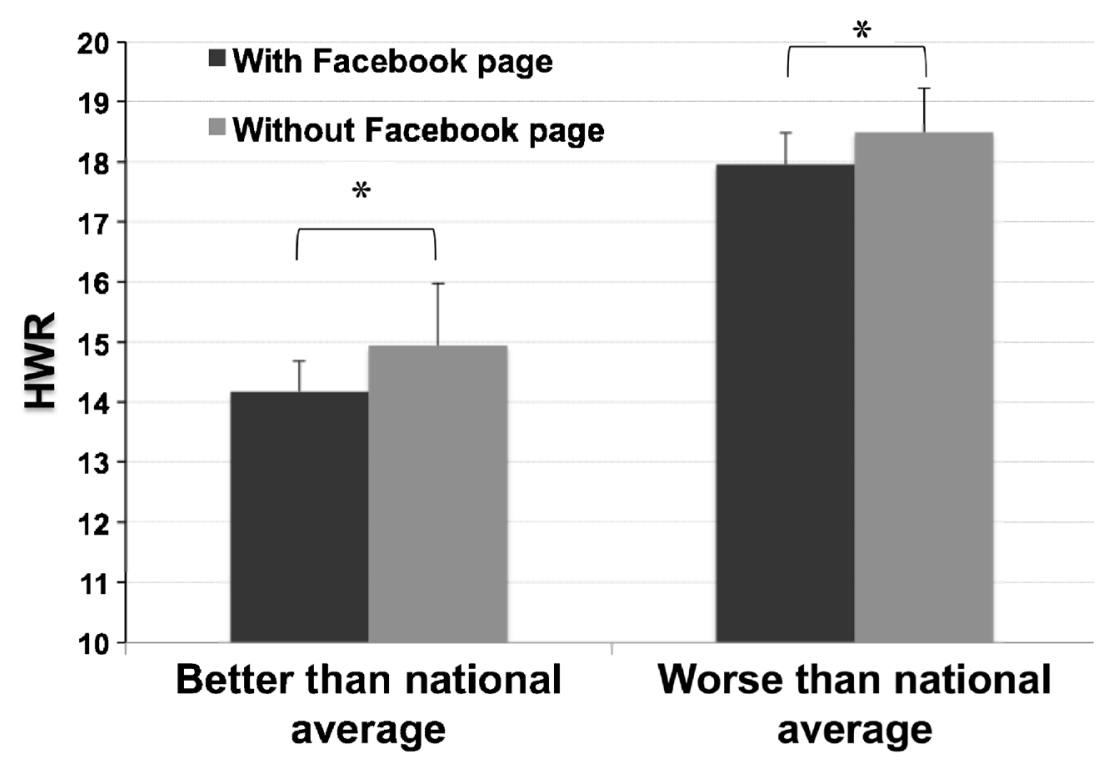

Within each group (better or worse than the national average), hospitals with a Facebook page had significantly lower 30-day hospital-wide unplanned readmission rates compared to those without a Facebook page.

*: $p<0.01$

Bars are means and handles are standard deviations

Figure 1. Comparison of 30-day hospital unplanned readmission rates, stratified by use of Facebook.

hospitals (mean: $4.15 \pm 0.31$, range: 3.1-5.0, median/ interquartile range: 4.2 [4.0-4.3]) was significantly $(p<0.01)$ higher than that for high-HWR hospitals (mean: $4.05 \pm 0.41$, range: $2.5-5.0$, median/interquartile range: 4.1
[3.8-4.3]). There was no significant difference between groups for the following Facebook variables: number of likes, number of check-ins, and number of months the Facebook page existed.

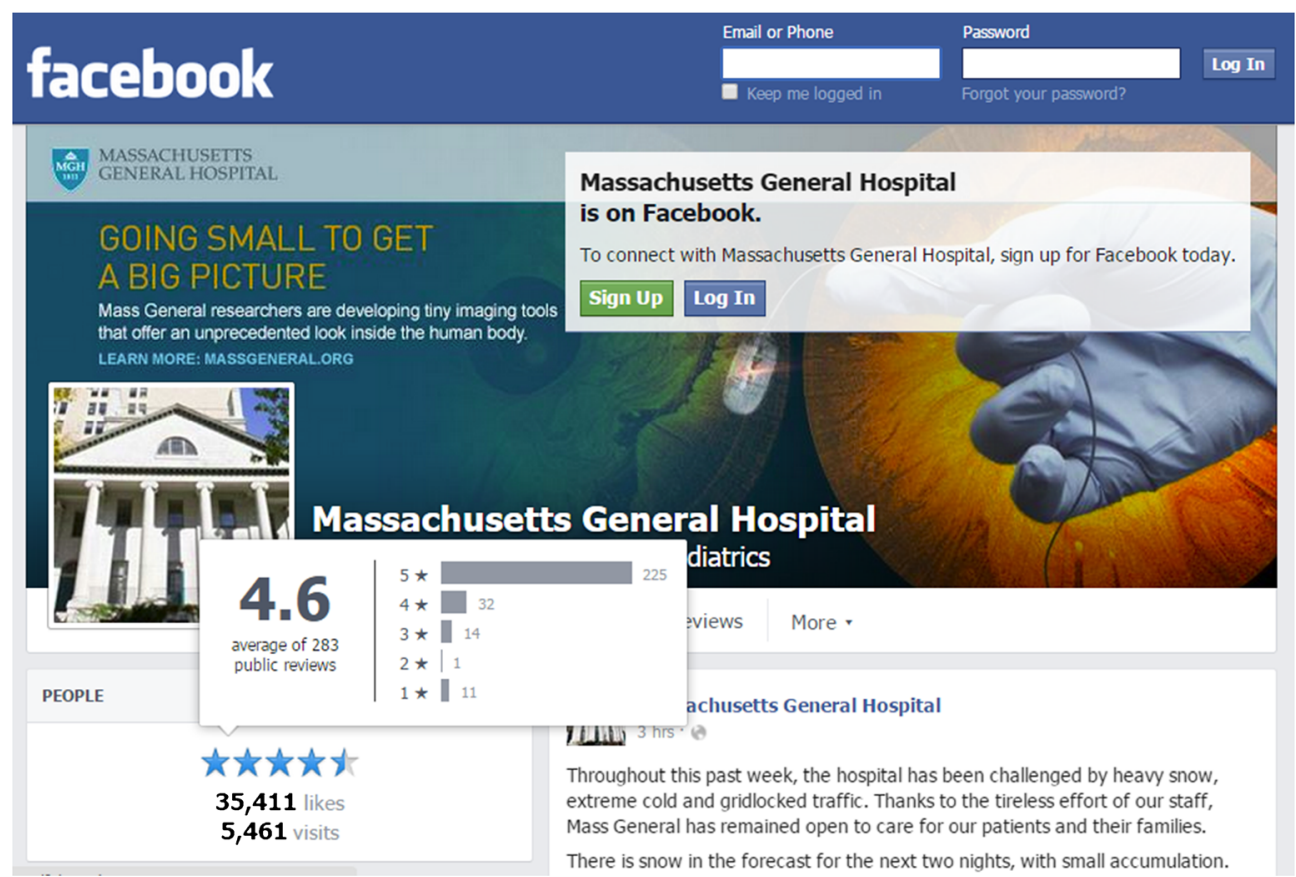

Figure 2. Massachusetts General Hospital Facebook page. *accessed on 2/4/2015 at www.facebook.com/massgeneral. 
Table 3 Multivariate Regression Analysis for Prediction of Performance on 30-Day Hospital Readmissions (Better or Worse than National Average)

\begin{tabular}{lclll}
\hline \hline & $\begin{array}{l}\text { Odds } \\
\text { Ratio }\end{array}$ & $\begin{array}{l}\text { 95\% } \\
\text { Confidence } \\
\text { Interval }\end{array}$ & P value \\
\cline { 3 - 4 } & & Lower & Upper & \\
\hline Number of admissions & 1.0 & 1.0 & 1.0 & $\mathrm{NS}$ \\
Total expenses (\$ millions) & 1.0 & 1.0 & 1.0 & $\mathrm{NS}$ \\
$\begin{array}{l}\text { Teaching affiliation } \\
\text { (major vs. minor/none) }\end{array}$ & 14.3 & 5.55 & 33.3 & $<0.01$ \\
Total number of beds & 1.0 & .99 & 1.01 & $\mathrm{NS}$ \\
Number of personnel & 1.0 & .99 & 1.0 & $\mathrm{NS}$ \\
Number of outpatient visits & 1.0 & 1.0 & 1.0 & $\mathrm{NS}$ \\
Months on Facebook & 1.0 & .9 & 1.0 & $\mathrm{NS}$ \\
Rating out of five & 5.131 & 2.559 & 10.285 & $<0.01$ \\
Number of likes & 1.0 & 1.0 & 1.0 & $\mathrm{NS}$ \\
Number of check-ins & 1.0 & 1.0 & 1.0 & $\mathrm{NS}$ \\
\hline
\end{tabular}

Odds ratios are calculated for better $(n=207)$ vs. worse $(n=203)$ than national average hospitals with ratings available on Facebook.

Better or worse than national average categories denote hospitals with low or high $H W R$, respectively.

NS nonsignificant

Figure 2 presents an in-group comparison of 30-day HWR stratified by the presence or absence of a Facebook page. Among high-HWR hospitals, those with a Facebook page $(n=300)$ had a lower HWR than those without a Facebook page $(n=64)(17.96 \pm 0.73$ vs. $18.5 \pm 1.04, p<0.01)$. Among lowHWR hospitals, those with a Facebook page $(n=294)$ had a significantly lower HWR than hospitals in this group without a Facebook page ( $n=21)(14.17 \pm 0.53$ vs. $14.94 \pm 0.52)$.

In multivariate logistic regression analysis (Table 3), a one-star increase in Facebook rating was associated with a 5.1-fold greater likelihood that the hospital was a lowHWR hospital versus a high-HWR hospital, when controlling for hospital characteristics (admissions, number of beds, number of personnel, number of outpatient visits) and Facebook-related variables. A major teaching affiliation was associated with increased odds of belonging to the high-HWR hospital group (OR=14.3, CI: 5.633.3, $p<0.01)$.

\section{DISCUSSION}

This study examined the extent to which hospital ratings on Facebook were related to 30-day hospital-wide unplanned readmission rates among hospitals with readmission rates outside the confidence interval for the national average. Among hospitals with Facebook pages, those with lower 30day readmission rates had higher ratings on Facebook's fivestar rating scale than hospitals with higher readmission rates, after controlling for hospital characteristics and Facebookrelated variables. These findings add support to the small but growing body of literature suggesting that unsolicited feedback on social media and hospital ratings sites corresponds to patient satisfaction and objective measures of hospital quality. ${ }^{11,23,31}$
Secondly, $88 \%$ of hospitals in this study had a Facebook page, which is similar to estimates published in other studies. ${ }^{32}$ This finding suggests that hospital leaders find value or necessity in maintaining a social media presence. Healthcare organizations are using social media sites like Facebook for a variety of functions, including patient education, marketing, and sharing information with staff. ${ }^{33}$ Healthcare organizations may find that allowing ratings on social media sites warrants increased attention.

There are several plausible explanations for the finding that Facebook ratings were associated with 30-day HWR. First, consumer ratings of hospitals on social media may actually reflect hospital quality. The concept that user-generated and unsolicited feedback reflects quality is not novel, having been demonstrated in the automotive and restaurant industries. ${ }^{20,34}$ Alternatively, ratings could reflect confirmation bias, as users may be inclined to provide higher ratings to hospitals already perceived to be of high quality.

While Facebook users are now empowered to provide hospital ratings, the variables coalescing into the final rating could be quite varied. Other ratings sites/systems such as U.S. News \& World Report ${ }^{\circledR}$ and the Leapfrog hospital survey have more granularity, as they provide information on organ system, disease process, or aggregates of multiple quality measures. Another benefit of more granular systems is periodic updates. In contrast, social media ratings may be more difficult to change once a critical mass of feedback is met. Thus, Facebook ratings could reflect historical and not current trends in quality.

Low-HWR hospitals were more likely to have a Facebook page than high HWR hospitals, which could be attributable to the fact that hospitals with high HWR may have more to lose from potential negative feedback. The impact of negative ratings on social media may be more detrimental than the influence of potentially positive ratings/feedback. ${ }^{36}$ Alternatively, lower-quality hospitals may have a perceived or real lack of necessity to maintain a social media presence, as they may be situated in regions where competition for patients or insurance contracts is limited. Finally, maintaining a coherent social media strategy requires resources that hospital leaders may determine are better served elsewhere, such as programs to improve quality and safety.

Quantitative study of the relationship between usergenerated ratings/feedback on social media and hospital quality measures is relatively new within healthcare ${ }^{11}$. However, interest in the role of social media in assessing patient satisfaction and hospital quality is growing. ${ }^{11}$ The findings in our study are similar to those of others in both the U.S. and UK, suggesting that unsolicited ratings and feedback are associated with patient satisfaction and objective measures of quality. One study evaluated the relationship between hospital ratings on Yelp and those on the Hospital CAHPS ${ }^{\circledR}$ (HCAHPS; Hospital Consumer Assessment of Healthcare Providers and Systems) survey. ${ }^{23}$ Over 950 hospitals had at least five ratings on Yelp, and there was a positive correlation between ratings 
and higher scores on HCAHPS. Similarly, ratings were negatively correlated with mortality measures for myocardial infarction and pneumonia and 30-day readmissions. ${ }^{23}$

In 2008, the UK National Health Service (NHS) established the Web site "NHS Choices," allowing patients to provide unsolicited ratings of their experiences with healthcare providers $^{37}$. Patients can rate several aspects of quality and can leave comments on particular aspects in free text. A study of hospital ratings within NHS Choices found that positive recommendations were significantly associated with lower standardized mortality ratios and lower readmission rates. ${ }^{32}$ Similarly, higher ratings of hospital cleanliness were associated with lower methicillin-resistant Staphylococcus aureus (MRSA) and Clostridium difficile infection rates. ${ }^{32}$

In our study, there was no association between the number of likes and hospital-wide 30-day unplanned readmission rates. This is in contrast to a study of New York City area hospitals that found a strong negative association between the number of Facebook "likes" and 30-day mortality rates and a positive association with patient recommendation measures. ${ }^{38}$ One possible explanation is that mortality may have a stronger influence on whether users "like" a hospital Facebook page. However, within the social media landscape, ratings are now considered to be more representative of consumer ideas about quality than about "likes."19 Facebook's five-star rating system combines ease of use, quantitative information, and digestibility, offering more granularity with regard to how users feel about companies and products. ${ }^{19}$

Evaluating the relationship between user-generated ratings of hospitals on social media and objective measures of hospital quality is important given the potential impact on consumer healthcare decisions. Rothberg notes that although even the best public reports of hospital quality do not seem to affect market share or consumer choices, this may change as consumers become more aware of rating services and as high-deductible plans drive patients to seek care beyond their local hospital. ${ }^{15}$

Ratings on social media represent another tool that consumers can employ in making healthcare decisions about hospitals. Along the spectrum of online tools that provide hospital ratings/rankings, social media is likely among the easiest to use and most readily accessible. Continuing to develop quality measures that are understandable and accessible to patients is important in order to ensure that measures on social media do not become overvalued, given inherent biases related to online ratings. Alternatively, incorporating social media and other online tools that allow consumers to provide feedback within existing quality measure platforms, similar to NHS Choices in the United Kingdom, may represent a reasonable next step.

\section{LIMITATIONS}

A number of limitations and confounders are present in the current study. First, the study design is cross-sectional and correlative, which limits assigning causality in the findings. Reporting of 30-day readmission measures are significantly delayed, and the most recently available data collection period at the time of the study (July 2011-June 2012) was before Facebook implemented the rating system. Therefore, Facebook ratings may not be pertinent to the time period of readmission data collection.

The Centers for Medicare \& Medicaid Services (CMS)/Yale 30-day all-cause unplanned readmission rate (HWR) used in this study has inherent limitations, including case mix adjustment, sample size, and concerns with applicability to nonMedicare populations. ${ }^{39}$ Another important limitation is that quality measures such as mortality or patient satisfaction were not utilized in addition to readmission rates. However, 30-day HWR was the only relevant hospital-level all-cause quality measure reported as a continuous variable on Hospital Compare. Mortality measures on Hospital Compare are condition-specific (e.g., 30-day mortality rate for heart failure or acute myocardial infarction). Alternatively, patient satisfaction measures from HCAHPs are reported as ordinal data (e.g., percentage of patients rating the hospital as a $0-6,7-8$, or 9 10 ), which limits quantitative discrimination amongst outliers in performance.

Excluding hospitals performing within the expected range of the national average for 30-day HWR has some weaknesses, including limiting the ability to evaluate for a potential correlation between ratings on Facebook across a representative sample of all hospitals. However, as a pilot study, the present evaluation of potential differences among outliers in performance may inform and direct a more comprehensive evaluation of Facebook ratings for a larger sample of hospitals that includes additional quality and satisfaction indicators.

User-generated feedback on Facebook may be biased and not reflective of patient experiences, and it could also be subject to fraud. Further, users providing feedback may not represent patients or families who received care at a particular institution. Also, individuals who use social media are not necessarily representative of the overall population, since the elderly and ethnic minorities are underrepresented in Internet use. ${ }^{40}$ Moreover, Facebook ratings do not provide a time scale, and thus a critical mass of ratings may drown out recent ratings that may be more representative of current quality or satisfaction. Lastly, while the difference in Facebook ratings between high- and low-HWR groups was statistically significant, exactly how meaningful the difference is remains unclear and may warrant further study.

\section{CONCLUSIONS}

The use of social media, particularly Facebook, is prevalent among U.S. hospitals. Further, hospitals with lower rates of 30-day hospital-wide unplanned readmissions have higher ratings on Facebook than hospitals with high readmission rates. The potential impact of social media ratings on 
healthcare consumer decision-making must not be underestimated in this changing healthcare environment with increased attention to cost and quality.

Conflict of Interest: There are no potential conflicts of interest. All authors will complete and submit the ICMJE form for Disclosure of Potential Conflicts of Interest.

Corresponding Author: McKinley Glover, MD MHS; Department of Radiology, Massachusetts General Hospital, Harvard Medical School, Boston, MA, USA (e-mail: mckinley.glover@mgh.harvard.edu).

\section{REFERENCES}

1. Ballve M. Our List Of The World's Largest Social Networks Shows How Video, Messages, And China Are Taking Over The Social Web; http://www. businessinsider.com/the-worlds-largest-social-networks-201312\#ixzz3MRmgwjtG 2013; Accessed: February 2, 2015

2. Hawn C. Take two aspirin and tweet me in the morning: how twitter, facebook, and other social media are reshaping health care. Health Aff (Millwood). 2009;28(2):361-368.

3. Hader AL, Brown ED. Patient privacy and social media. AANA J. 2010;78(4):270-274.

4. Mattingly TJ, Cain J, Fink JL. Pharmacists on Facebook: online social networking and the profession. J Am Pharm Assoc (2003). 2010;50 (3):424-427

5. Gulick SL. Social media: a brave new world for doctors. J Am Coll Radiol. 2011;8(5):366-368.

6. DeCamp M, Koenig Tw, Chisolm MS. Social media and physicians' online identity crisis. JAMA. 2013;310(6):581-582.

7. Lane SH, Twaddell JW. Should social media be used to communicate with patients? MCN Am J Matern Child Nurs. 2010;35(1):6-7.

8. Salathé M, Freifeld CC, Mekaru SR, Tomasulo AF, Brownstein JS. Influenza A (H7N9) and the importance of digital epidemiology. N Engl J Med. 2013;369(5):401-404.

9. Merchant RM, Elmer S, Lurie N. Integrating social media into emergencypreparedness efforts. N Engl J Med. 2011;365(4):289-291.

10. Alexander DE. Social media in disaster risk reduction and crisis management. Sci Eng Ethics. 2013;20(3):717-33.

11. Verhoef LM, Van de Belt TH, Engelen LJ, Schoonhoven L, Kool RB. Social media and rating sites as tools to understanding quality of care: a scoping review. J Med Internet Res. 2014;16(2):e56.

12. Greaves F, Ramirez-Cano D, Millett C, Darzi A, Donaldson L. Harnessing the cloud of patient experience: using social media to detect poor quality healthcare. BMJ Qual Saf. 2013;22(3):251-255.

13. Ricciardi L, Mostashari F, Murphy J, Daniel JG, Siminerio EP. A national action plan to support consumer engagement via e-health. Health Aff (Millwood). 2013;32(2):376-384.

14. Landro L. Social Networking Comes to Healthcare. Wall Street Journal 2006. http://www.wsj.com/articles/SB116717686202159961. Accessed: February 2, 2015

15. Rothberg MB, Morsi E, Benjamin EM, Pekow PS, Lindenauer PK. Choosing the best hospital: the limitations of public quality reporting. Health Aff (Millwood). 2008;27(6):1680-1687.

16. Fung CH, Lim YW, Mattke S, Damberg C, Shekelle PG. Systematic review: the evidence that publishing patient care performance data improves quality of care. Ann Intern Med. 2008;148(2):111-123.

17. Huckman RS, Kelley MA. Public reporting, consumerism, and patient empowerment. N Engl J Med. 2013;369(20):1875-1877.

18. Kaiser Family Foundation. 2008 Update on Consumers' Views of Patient Safety and Quality Information. 2008. https://kaiserfamilyfoundation. files.wordpress.com/2013/01/7819.pdf. Accessed: February 2, 2015
19. Etherington D. A Like Is Not Enough: Facebook Tests Star Ratings Displayed On Pages. Techcrunch; 2013. http://techcrunch.com/2013/ 11/07/facebook-pages-star-ratings/. Accessed: February 2, 2015

20. Luca M. Reviews, Reputation, and Revenue: The Case of Yelp.com Harvard Business School; 2011 . http://www.hbs.edu/faculty/ Publication\%20Files/12-016_0464f20e-35b2-492e-a328-fb14a325f718. pdf. Accessed: February 2, 2015

21. Lagu T, Hannon NS, Rothberg MB, Lindenauer PK. Patients' evaluations of health care providers in the era of social networking: an analysis of physician-rating websites. J Gen Intern Med. 2010;25(9):942-946.

22. Greaves F, Laverty AA, Cano DR, et al. Tweets about hospital quality: a mixed methods study. BMJ Qual Saf. 2014;23(10):838-846.

23. Bardach NS, Asteria-Peñaloza R, Boscardin WJ, Dudley RA. The relationship between commercial website ratings and traditional hospital performance measures in the USA. BMJ Qual Saf. 2013;22(3):194-202.

24. Berenson RA, Paulus RA, Kalman NS. Medicare's readmissions-reduction program-a positive alternative. N Engl J Med. 2012;366(15):1364-1366.

25. Centers for Medicare and Medicaid. Official Hospital Compare Data. https:// data.medicare.gov/data/hospital-compare. Accessed: February 2, 2015

26. National Quality Forum. Endorsement Summary: All Cause Readmissions. 2012. https://www.qualityforum.org/News_And_Resources/Endorsement_Summaries/All-Cause_Readmissions_Endorsement_Summary. aspx. Accessed: February 2, 2015

27. Centers for Medicare and Medicaid. Hospital Compare Measure Dates. https://data.medicare.gov/Hospital-Compare/Measure-Dates/4j6d-yzce. Accessed: February 2, 2015

28. Centers for Medicare and Medicaid. Hospital Compare: 30 day unplanned readmission and death measures. http://www.medicare.gov/ hospitalcompare/Data/30-day-measures.html Accessed: February 2, 2015

29. Pineda N. Facebook Tips: What's the Difference between a Facebook Page and Group? 2010; https://www.facebook.com/notes/facebook/facebooktips-whats-the-difference-between-a-facebook-page-and-group/ 324706977130 Accessed: February 2, 2015

30. American Hospital Association - AHA Dataviewer. 2014; http://www. ahadataviewer.com/ Accessed: February 2, 2015

31. Centers for Medicare and Medicaid. Hospital Compare: Footnotes. http:// www.medicare.gov/hospitalcompare/data/Footnotes.html Accessed: February 2,2015

32. Greaves F, Pape UJ, King D, et al. Associations between Web-based patient ratings and objective measures of hospital quality. Arch Intern Med. 2012; 172(5):435-436.

33. Griffis HM, Kilaru AS, Werner RM, et al. Use of social media across US hospitals: descriptive analysis of adoption and utilization. J Med Internet Res. 2014;16(11):e264.

34. Galloro v. Status update. Hospitals are finding ways to use the social media revolution to raise money, engage patients and connect with their communities. Mod Healthc. 2011;41(11):6. -7, 16, 11.

35. Abrahams AS, Jiao J, Wang GA, Fan W. Vehicle defect discovery from social media. Decis Support Syst. 2012;54(1):87-97.

36. Murphy I. Social Media Matters for Radiologists. 2013; http://www. diagnosticimaging.com/rsna-2013/social-media-matters-radiologists. Accessed: February 2, 2015

37. Greaves F, Pape UJ, King D, et al. Associations between internet-based patient ratings and conventional surveys of patient experience in the English NHS: an observational study. BMJ Qual Saf. 2012;21(7):600-605.

38. Timian A, Rupcic S, Kachnowski S, Luisi P. Do patients "like" good care? measuring hospital quality via facebook. Am J Med Qual. 2013;28(5):374382 .

39. Horwitz L, Grady J, Dorsey K, et al. 2014 Measures Updates and Specifications Report Hospital-Wide All-Cause Unplanned Readmission Version 3.0. Yale New Haven Health Services Corporation/Center for Outcomes Research \& Evaluation (YNHHSC/CORE) 2014

40. Moorhead SA, Hazlett DE, Harrison L, Carroll JK, Irwin A, Hoving C. A new dimension of health care: systematic review of the uses, benefits, and limitations of social media for health communication. J Med Internet Res. 2013;15(4):e85. 